Pardo Barrionuevo, C.A. (2019): “Propiedades, tributos y templos en los territorios feniciosoccidentales".Spal28.2:165-180.DOI:http://dx.doi.org/10.12795/spal.2019.i28.18

\title{
PROPIEDADES, TRIBUTOS Y TEMPLOS EN LOS TERRITORIOS FENICIOS OCCIDENTALES
}

\section{LAND OWNERSHIP, TAXES AND TEMPLES IN WESTERN PHOENICIAN TERRITORIES}

\author{
CARMEN ANA PARDO BARRIONUEVO \\ Universidad de Almería, Departamento de Geografía, Historia y Humanidades \\ Carretera de Sacramento s/n, Edificio C de Humanidades, despacho 2.46, C.P. 04120, Almería (Almería, España) \\ Correo-e: cpb868@ual.es (D) https://orcid.org/0000-0002-7562-5756
}

\begin{abstract}
Resumen: En este artículo tratamos los territorios pertenecientes a las poblaciones fenicias occidentales: fronteras, producción, rentabilidad y fiscalización. En primer lugar, analizamos los tipos de propiedades fenicias en el Mediterráneo occidental en función de sus dimensiones y sus cultivos a partir de los testimonios arqueológicos. A continuación, exponemos las funciones de las magistraturas relacionadas con el control territorial y el cobro de impuestos. Finalmente, comprobamos la relación entre la religión fenicia y el territorio en el I milenio a.C.
\end{abstract}

Palabras clave: Territorio fenicio, tributos, propiedades, templos, santuarios, magistraturas fenicias

\section{INTRODUCCIÓN Y JUSTIFICACIÓN}

El uso y productividad de las tierras en el ámbito fenicio occidental ha sido un tema tratado tangencialmente en la historiografía contemporánea. Sin embargo, la política administrativa de las ciudades fenicias estuvo ligada al reparto, control y fiscalización de los territorios próximos desde los primeros años de ocupación. En la actualidad, gracias al registro arqueológico de prospecciones superficiales y a las publicaciones de analíticas

\begin{abstract}
In this paper we deal with the Landscape of the Western Phoenician populations: borders, production, profitability yield rate and economic control and supervision. Firstly, we will discuss the types of Phoenician properties in the Western Mediterranean depending according on to their dimensions and their cultures crops from archaeological evidence. After that, Then we discuss the functions of the magistrates related to territorial control and taxation. Finally, we check the relationship between Phoenician religion and territory in during the first millennium BC.
\end{abstract}

Keywords: Phoenician territory, taxes, properties, temples, sanctuaries, Phoenician magistrates

orgánicas, podemos intuir la dedicación y extensión de las propiedades agrícolas. Por otra parte, los testimonios epigráficos y varios autores clásicos dan fe del interés de los gobiernos fenicios en el control y pago de tributos a través de la implantación de cargos especializados. La religión fenicia completaría el entramado político y económico del territorio con templos y santuarios situados estratégicamente en las vías de comunicación para la protección de las transacciones económicas y, a veces, para salvaguardar algunos acuerdos políticos bilaterales. 


\section{LA DIVISIÓN DEL TERRITORIO FENICIO OCCIDENTAL}

Sabemos que las colonias fenicias occidentales, algunas con cronologías que remontan al siglo IX a.C., explotaron el territorio próximo desde el inicio del proceso colonizador, pero no sería hasta el siglo VI a.C. cuando se transformaron en verdaderas ciudades estado o poléis (Th. VI, 2, 6; Arist. Pol. II, 8, 1; Arteaga 1994: 37-48; López Castro 2004: 152-153; Ferrer Albelda y García Fernández 2007: 663-664). Este proceso ha sido definido como una "regionalización" o un fraccionamiento político del Mediterráneo (Ferrer Albelda 2017: 172 y 182-184) donde cada ciudad tendría un distrito territorial denominado $\mathrm{gbl}$ o $\mathrm{mqm}$ para la explotación de la tierra o 'rşs (Krahmalkov 2000: 73, 134 y 307-308). Esta área ha sido definida por algunos autores (Alvar y González Wagner 1988: 172) como el "cinturón agrícola suburbano" y conformaría el espacio entre la necrópolis colonial y el asentamiento principal (Delgado 2007: 37), es decir, aproximadamente un radio máximo de $15 \mathrm{~km}$ repartido en pequeñas parcelas. Más allá de este límite, la tierra estaría dividida en latifundios para la producción agrícola excedentaria (Alvar y González Wagner 1988: 178 y 174).

Podemos cuantificar el grado de explotación del territorio y su degradación gracias a los análisis carpológicos, polínicos y antracológicos. Un ejemplo sería el territorio de Baria, donde los análisis de los siglos VII-III a.C. abogan por la proximidad de los campos de cultivo situados en las zonas más bajas (López Castro 2003: 97-98). Otro caso sería la ribera del Guadiana, que pasó de tener olmos y fresnos durante el Bronce Final, a sufrir una deforestación en favor del cultivo mayoritario de cereales durante el Hierro I coincidiendo con los primeros contactos fenicios (Hernández Carretero 2008: 140). La misma tendencia de supresión de la cubierta vegetal para los cultivos de cereales y olivos ha sido registrada en Carteia durante los siglos IV y III a.C. (López García y Hernández Carretero 2006). En otros casos, como en Toscanos, el propio espacio urbano quedó dividido en unidades de suelo donde habría una vivienda y una huerta (Alvar y González Wagner 1988: 172).

El territorio quedaría dividido en propiedades privadas (Arteaga 1994: 34) o grl (Krahmalkov 2000: 143 ) adquiridas por métodos violentos, por compra, por pactos o alianzas desiguales (López Castro 2000: 126; González Wagner 2006: 195). La compra de la tierra debió de ser uno de los principales métodos de adquisición y conservamos la denominación exacta de esta transacción: $k r y$ (Krahmalkov 2000: 241). Esta palabra surgiría de la necesidad de establecer un término jurídico para regular esta acción de forma legal. Seguramente, la forma de proceder sería similar al testimonio tardío del ostrakon con grafía fenicia del siglo I d.C. encontrado en al-Qușbāt (Msellata). Este texto fue escrito posiblemente por un administrador y ha sido interpretado como un documento económico para la compra de una propiedad agrícola entre dos hombres con antropónimos fenicios. El precio de esta propiedad quedó fijado en 5 prșm y 10 talentos de pasas (Levi della Vida y Amadasi Guzzo 1987: 131-133).

Como ya hemos advertido, la mayor parte de las propiedades serían pequeñas parcelas destinadas a cultivos básicos para la alimentación durante los primeros siglos (Gsell 1972: 20-22; López Castro 1995: 46). Sin embargo, las fincas serían esenciales para la producción excedentaria de alimentos, sobre todo aceite y vino, envasada y distribuida en ánforas fabricadas desde el siglo VIII a.C. en Occidente (Alvar y González Wagner 1988: 174; González Wagner 1989: 91-92 y 100). Las parcelas pudieron estar delimitadas por vallas y tener instalaciones básicas como un pozo y un cobertizo para las herramientas (Van Dommelen y Gómez Bellard 2008a: 214 y 216). Así, la cerámica sin asociación a restos inmuebles documentada en las prospecciones podría ser un indicio de la instalación de almacenes temporales para las labores del campo o de lugares de estabulación de animales. Desgraciadamente, esta hipótesis no se puede demostrar a partir del actual registro arqueológico (Van Dommelen y Gómez Bellard 2008b: 16).

Debido a que la producción agrícola estuvo condicionada por la rentabilidad del cultivo según el tipo de suelo, y con el fin último de sacar el máximo aprovechamiento de terrenos improductivos para otras actividades, las poblaciones rurales fenicias estuvieron especializadas y vinculadas entre sí a través de una extensa red comercial. Este sistema económico permitió superar los periodos de escasez y palió la falta de alimentos en zonas más desfavorecidas o dedicadas a otras actividades económicas. Además, desde el inicio de la colonización, el territorio fenicio consolidó las formas de dependencia entre los centros menores y el núcleo urbano principal gracias a la instalación generalizada de un templo principal donde se velaría por la equidad en las transacciones económicas. No obstante, la generalización sistemática de pequeñas instalaciones agrícolas o granjas se produjo durante los siglos IV-II a.C. y, posiblemente, estuvieron administradas directamente por el propietario como aconsejaba el agrónomo 
cartaginés Magón (Colum. I, 18; Plin. H.N. XVIII, 7, $35)$. Por otra parte, algunas ciudades pudieron funcionar como "agro-ciudades" donde la mayor parte de la población serían campesinos que se desplazarían para trabajar la tierra (Van Dommelen y Gómez Bellard 2008b: 16). Un buen ejemplo de estas prácticas serían las ciudades de la isla de Djerba durante los primeros siglos de ocupación fenicia (Fentress 2009: 73).

La explotación del territorio comprendía el aprovechamiento de amplios espacios comunales dedicados al pastoreo, la caza o la recolección. Esta área no ha sido constatada físicamente en ningún estudio arqueológico, pero sin duda, las zonas abruptas y montañosas y las tierras menos fértiles estarían dedicadas a estas labores. Una prueba indirecta de la importancia de estos lugares sería el significativo comercio de conservas cárnicas desarrollado en Cerdeña (Pardo 2015: 175-176) gracias a la ganadería practicada en las zonas no agrícolas.

Uno de los territorios más ampliamente estudiados por la historiografía contemporánea sería el de Cartago. Éste fue definido por los autores clásicos como chora y, raras veces, como eparquía o "provincia". Así, Tito Livio (XXIX, 3, 13; XXIX, 30, 10; XXIX, 31, 10; XXX, $7,8)$ empleó el término urbs o ager para los territorios de Cartago antes del 202 a.C. Sin embargo, Polibio (XV, 18, 1; XXI, 21) usaría la palabra chora para el periodo posterior al 201 a.C. cuando Roma comenzó a organizar los territorios cartagineses conquistados (Crouzet 2003: 672-673). Su área de control llegaría hasta Megara y Kerkuán y estaría dividida en propiedades de mediano tamaño dedicadas principalmente al cultivo de verduras y árboles y granjas ganaderas. Serían parcelas muy fértiles y prósperas separadas entre sí por paratas de piedra seca y plantas espinosas. Además, estarían abastecidas de agua por tortuosas canalizaciones de irrigación (App. Lib., 69; Pun., 118, 559).

Las tierras explotadas por la ciudad norteafricana de Cartago serían el Tell tunecino, el valle del Medjerba, el Cabo Bon y la parte septentrional de Sahel (Picard y Picard 1982: 85). El estudio de Manfredi (2010: $330-332$ y 334 ) sobre la evolución del territorio cartaginés diferenció varias fases. En la primera etapa, Cartago organizó el territorio más próximo de Cabo Bon, los distritos de Muxsi, Zeugei y, quizás, Bizacena desde finales del siglo VI al siglo IV a.C. Posiblemente, la gestión de las áreas agrícolas de Muxsi y Zeugei recaería sobre poblaciones autóctonas con las que Cartago estableció una relación de clara ventaja económica. Por el contrario, la clase alta de Bizacena asumió el papel de clase dirigente intermedia y recreó allí el sistema latifundista púnico. La segunda fase (siglos IV y III a.C.) está caracterizada por la máxima expansión cartaginesa con la anexión de Campii Magni, los distritos Gunzuzi y Thuscae hasta la denominada Fosa Fenicia (fig. 1). El distrito de Gunzuzi sería un buen ejemplo de la colonización agrícola de Cartago desde el siglo IV a.C. realizada por ciudadanos cartagineses que actuaban como representantes estatales en la administración y control territorial. Por su parte, la anexión del Pagus Thuscae pudo producirse por la necesidad de Cartago de compensar la pérdida de la producción agrícola de Cerdeña a partir del 237 a.C. Este distrito pudo estar compuesto por unidades administrativas menores debido al uso en plural del término ' $r s ̣$ en la inscripción de Djebel Massoudj. En la última etapa, Cartago perdió progresivamente parte del territorio por las conquistas de Masinisa desde finales del siglo III al 146 a.C.

Arqueológicamente, los monumentos turriformes construidos a partir del siglo IV a.C. pudieron servir como indicadores del territorio, límite fronterizo de la jurisdicción de las ciudades o marcador de los latifundios de adinerados terratenientes (Prados Martínez 2008: 141, 210-212, 275-279 y 291). Así, la distribución de estas construcciones parece responder a grandes dominios en los distritos de Muxsi (Peyras 1991: 206 y 492), Zeugei, Cabo Bon, Bizacena (Manfredi 2000: 234), la región de Hédil (Prados Martínez 2008: 279) y, quizás, la Pequeña Syrte (Crouzet 2003: 67677). Estas propiedades serían de las grandes familias vinculadas al gobierno cartaginés. Los casos más famosos son los latifundios de la familia hanónida, como los de Hanón el Grande (Ius. XXI, 4), o los de la familia bárquida como las tierras de Aníbal situadas entre Acholla y Thapsus (Liv. XXXIII, 48, 1), cerca de la costa (IUst. XXXI, 2, 3). Este linaje aprovecharía los nuevos mercados en la Península Ibérica para exportar el excedente de sus cultivos en el contexto de la II Guerra Romano-Cartaginesa (Martínez Hahnmüller 2016a: 136-137; 2016b: 176).

Por el contrario, en la banda costera y subcostera, el tamaño de las propiedades sería de pequeñas y medianas dimensiones dedicadas a la arboricultura y a la horticultura desde el siglo V a.C. (Bondì 1995c: 279). Este paisaje sería más evidente entre los siglos III y II a.C., cuando únicamente existiría una anecdótica representación latifundista (Kolendo 1965: 46-47 y 49-50; Tsirkin 1986: 130).

El cultivo mayoritario practicado en estas fincas pudo ser el olivo, al menos, desde el siglo VI a.C., cuando comenzó una progresiva sustitución de especies silvestres por Olea en las incineraciones del tophet de Salambó (Stuijts 1991: 59-61). El cultivo olivarero 


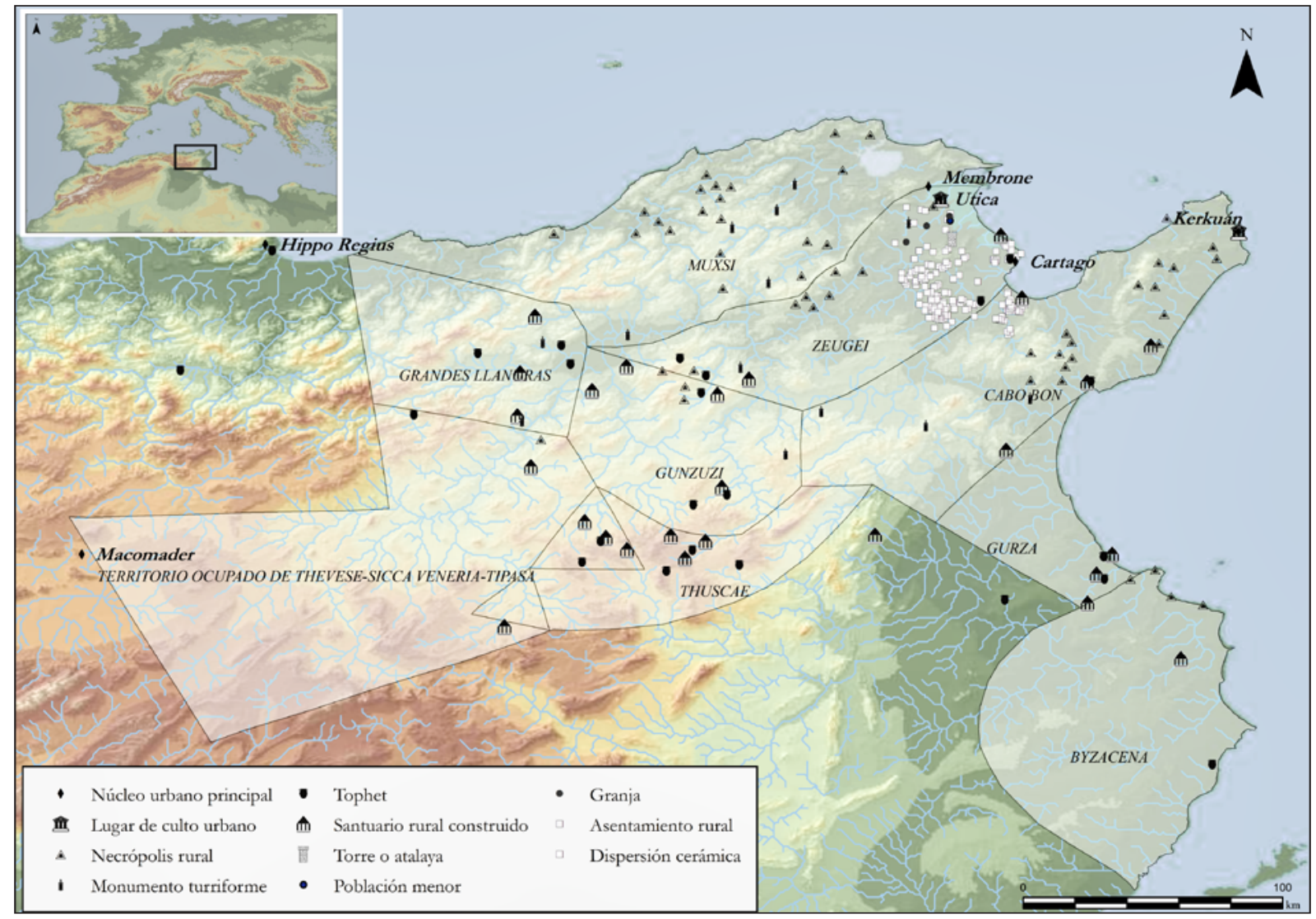

Figura 1. Asentamientos y distritos de Cartago entre los siglos IV y II a.C. (elaboración propia a partir de Ferchiou 1994; Chelbi, Paskoff y Trousset 1995; Ben Younès 1995; Manfredi 2003; Prados Martínez 2008; Ruiz Cabrero y Peña 2010).

requiere una menor cantidad de trabajadores, pero los años de improductividad agrícola son superiores a los de cualquier otro cultivo. Por este motivo, únicamente las personas adineradas pudieron asumir el coste de estas plantaciones (Wolff 1996: 130). Sin embargo, gracias a los beneficios del sector agrario, sobre todo arborícola, aumentó la estabilidad económica del Estado cartaginés (Picard y Picard 1982: 84-86).

Tradicionalmente, la principal característica de Cerdeña (fig. 2) es la capilaridad del territorio fenicio que abogaría, de manera general, por un modelo latifundista (Meloni 1975: 118 y 122-123; Bondì 1995b: 352; 1995c: 280-281). Sin embargo, esta misma implantación territorial impediría las grandes propiedades, al menos, en las provincias de Marmilla y Arbórea (Fantar 1993: 266; Van Dommelen 1998: 157). Un caso bien estudiado es el de Nora, donde proliferaron los enclaves agrícolas entre los siglos VI y IV a.C., en su mayoría con una extensión inferior a los $2000 \mathrm{~m}^{2}$. En cambio, otros de entre 5000 y $9000 \mathrm{~m}^{2}$, sugieren una explotación de tipo latifundista continuada hasta fechas romano-imperiales (Botto et al. 2003: 160, 180 y 183; Finocchi 2013: 171-173). Desde otra óptica, el número y la ubicación de establecimientos agrícolas dependientes de Nora inducen a pensar en una organización en torno a lugares centrales y un reparto de la tierra condicionado por la orografía y edafología de los suelos. En Terralba, el escaso número de necrópolis en relación a la alta densidad de centros habitacionales respaldaría una organización heterárquica del entorno más que la jerárquica del caso anterior (Van Dommelen 2006: 14; Van Dommelen y Gómez Bellard 2008a: 217 y 227).

El control político cartaginés desde el siglo IV a.C. en Sicilia favoreció la explotación latifundista caracterizada por lujosas villas. Este paisaje, más parecido a las zonas norteafricanas cartaginesas, contrastaría con la zona griega que compartiría similitudes con el noroeste sardo (Van Dommelen 2006: 24-25). Una excepción sería el territorio de Segesta, en Sicilia, donde, tras la toma cartaginesa a partir del siglo IV a.C., se llevaría 


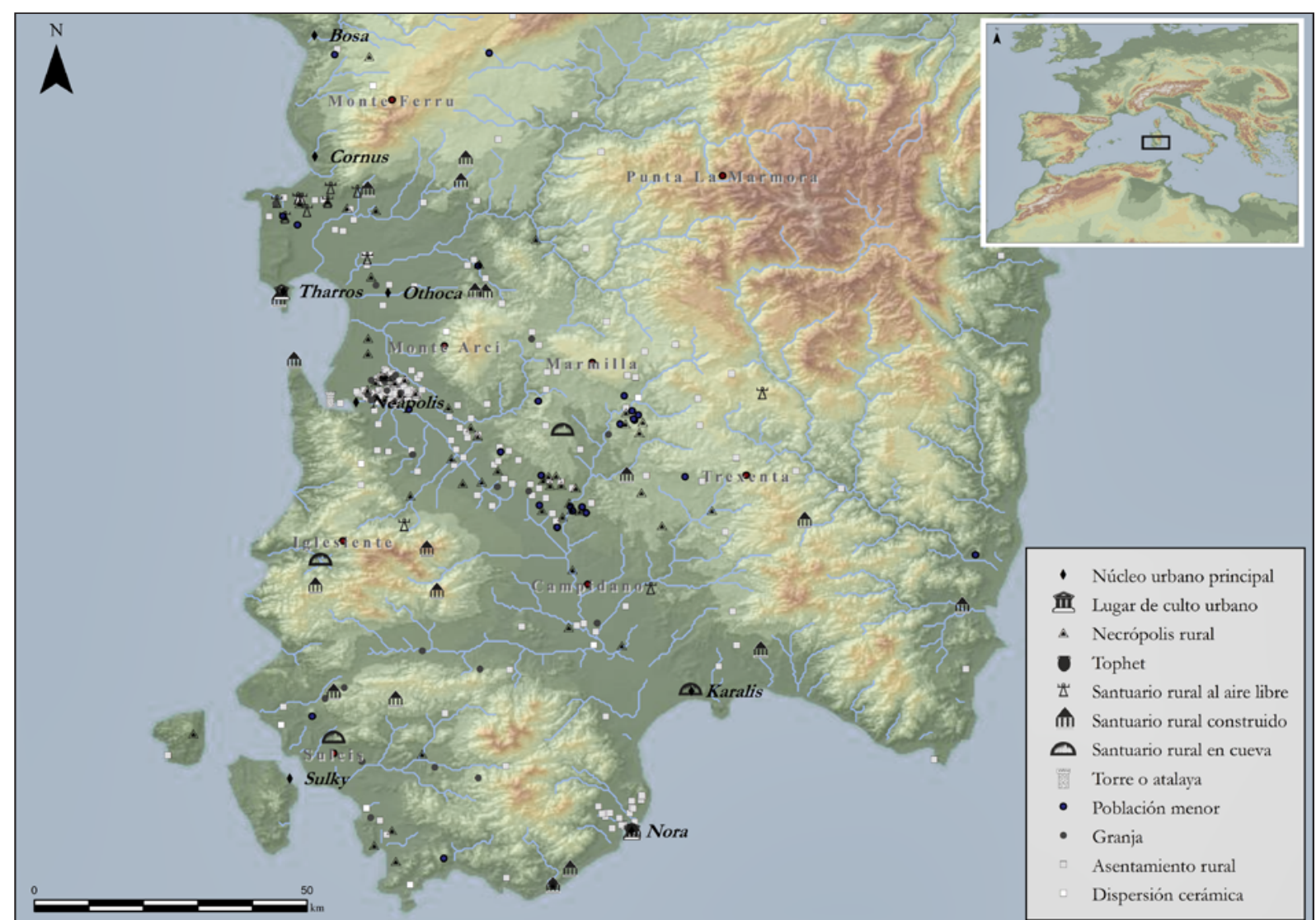

Figura 2. Distribución de los asentamientos fenicios en Cerdeña entre los siglos IV y III a.C. (elaboración propia a partir de Barreca 1988; Nieddu y Zucca 1991; Van Dommelen 1998; Bondì 2003).

a cabo una agricultura de pequeñas y medianas propiedades hasta, al menos, finales del siglo II a.C. (Bernardini et al. 2000: 99-101).

En Pantelleria, la falta de recursos hidráulicos naturales fue paliada por una densa red de cisternas (fig. 3). No obstante, no se podría efectuar una irrigación a gran escala y las propiedades serían de pequeños huertos (Castellani y Mantellini 2006: 119). En cuanto a los cultivos, el clima y el tipo de suelo volcánico pudieron haber favorecido las plantaciones de vid (Baldassari y Fontana 2006: 55).

En Malta (fig. 4), mayoritariamente se conocen necrópolis rurales por lo que las explotaciones rurales han sido interpretadas de diferente forma. Así, se ha defendido que pudieron ser minifundios en los que no se precisaría mano de obra esclava (Vidal González 1996: 98-99), o latifundios (Vella 2005: 445) creados por Cartago (Carretero 2007: 155, 211, 216, 220 y 223). La única instalación rural excavada, Ras Ir-Raћeb, fechada entre los siglos IV-III a.C., es un edificio cuadrangular con patio enlosado de mármol, una cisterna y estructuras de almazara (Buhagiar 1988: 69-70 y 72-76). Este edificio y el resto de datos arqueológicos abogan a que el archipiélago maltés se entendería como parte del sector cultural y geográfico definido por la costa del norte de África al este de Cartago (Ciasca 1995: 710). Además, los puestos de vigilancia como Mqabba, Cirkop, Safi, Zurrieg y Qrendi, fechados a partir del siglo IV a.C., han sido relacionados con el control de grandes propiedades de la aristocracia (Sagona 2002: 271).

Geográficamente, Ciasca (1995: 704-705) ha distinguido tres zonas: el espacio centro-oriental caracterizado por pequeños núcleos o pueblos contiguos dedicados a la pesca y la agricultura que llegarían a alcanzar una gran superficie (quizás por aglomeración o fusión) en época púnica y romana. La segunda zona, en la extremidad S-SE, tendría un gran núcleo poblacional costero favorecido por un puerto natural en torno al cual pudieron establecerse otros centros de diversos tamaños dedicados a actividades marítimas. Finalmente, 


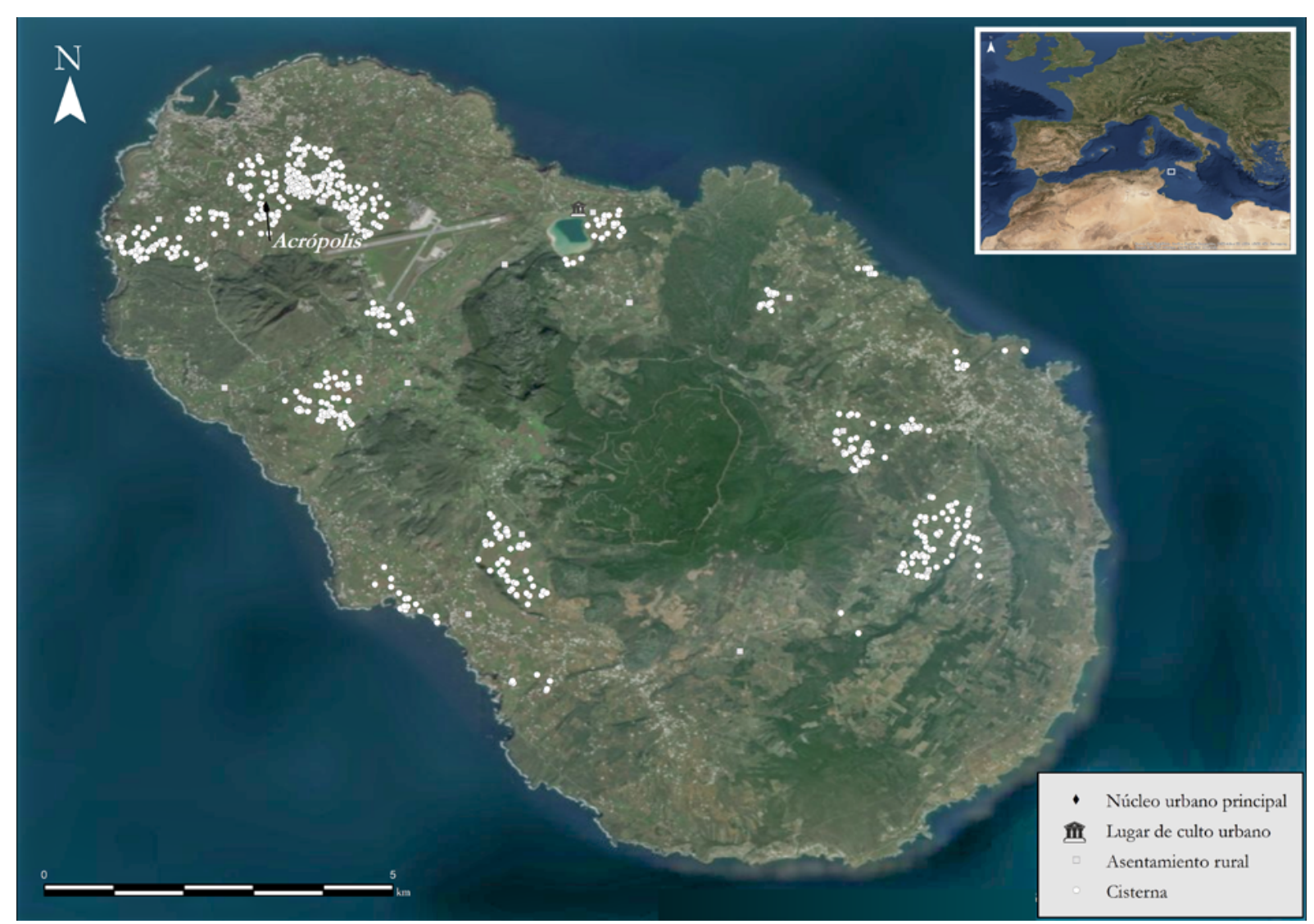

Figura 3. Distribución de los asentamientos fenicios de Pantellería entre los siglos IV y III a.C. (elaboración propia a partir de Baldassari y Fontana 2006: 57-58; Castellani y Mantellini 2006: 115).

la zona occidental estaría caracterizada por un terreno escarpado ligado al control y la defensa de la isla. Aquí, se han documentado numerosas tumbas y el principal núcleo fortificado.

La desigual investigación de los territorios fenicios nos impide obtener conclusiones generalizadas en la península ibérica. Sin embargo, contamos con tres ejemplos relativamente bien estudiados: Gadir, Malaka y Baria, donde se advierte un importante poblamiento en torno a la desembocadura de los principales ríos desde el inicio de la colonización. En los territorios de $\mathrm{Ga}$ dir (Barrionuevo 2001) y Malaka (Suárez et al. 2007), se ha registrado una gran variedad de tipos de población desde los primeros siglos, como asentamientos menores para el control del territorio, granjas y puestos de control y/o atalayas. La alta densidad poblacional aboga por una explotación de pequeñas parcelas. En el caso de Baria (Pardo 2015: 63-65, 98-100 y 127 130), por el contrario, durante todo el I milenio a.C. las poblaciones presentaban una mayor distancia entre ellas y podrían responder casi exclusivamente a poblaciones menores desde las que se explotó y controló el territorio, quizás en un régimen latifundista. Una excepción sería el entorno de la propia ciudad de Baria donde se instalaron pequeños asentamientos, como Cabecico de Parra, que únicamente explotarían las tierras más próximas.

Uno de los casos mejor estudiados arqueológicamente es Ibiza (fig. 5). El análisis de los centros rurales y la distancia entre ellos han permitido calcular el espacio cultivado con bastante fiabilidad. Así, en los asentamientos rurales de la zona de Cala d'Hort tendrían una superficie explotada de entre 20 y 25 ha (Ramon 1984: 32), los ubicados en el suroeste de la isla cultivarían entre 100 y 150 ha (Gómez Bellard 2000: 357), y disminuiría el tamaño de las explotaciones en el noreste (Gómez Bellard 2006: 184). Esta diferencia de tamaño puede ser debida al diferente uso de la tierra en función de la orografía (Gómez Bellard 2000: 357; 2008a: 74). Por otra parte, Plà de San Jordi, junto a la 


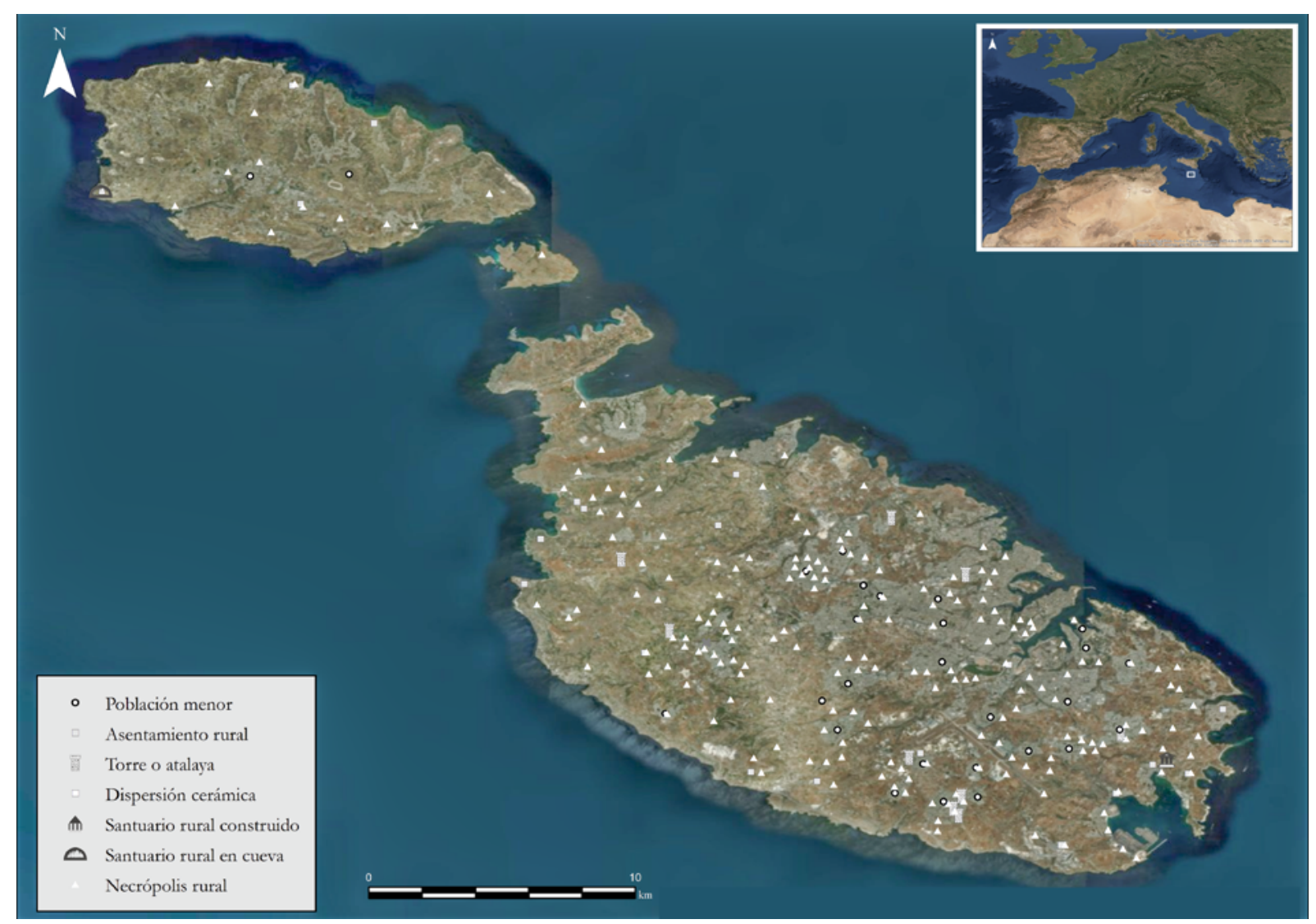

Figura 4. Distribución de los asentamientos fenicios en Malta y Gozo entre los siglos IV y III a.C. (a partir de Bonanno 2005; Sagona 2002).

ciudad de Ibiza, pudo tener una distribución parcelaria homogénea desde las primeras instalaciones del siglo $\mathrm{V}$ a.C. ya que estas tierras lindan con tres yacimientos coetáneos (González Villaescusa 2002: 253-254). La homogeneidad y adaptabilidad al terreno corroboraría el control de la ciudad en el establecimiento progresivo de la población rural (Costa 1998: 851-852; Costa et al. 2005: 1370).

En cuanto a la dedicación de las tierras ebusitanas, las prensas de aceite de época púnica y las marcas de cultivo excavadas en la base geológica señalan una explotación arborícola, sobre todo olivarera. Además, el uso coetáneo de dos tipos de marcas de cultivo con forma y dimensiones diferentes podría deberse a plantaciones de vides apoyadas sobre otros árboles que funcionarían a modo de tutores. El análisis polínico de la tierra de estas zanjas, fechado entre los siglos IV y I a.C., indicó mayoritariamente un cultivo de Olea/Phillyrea seguido de vid, cereales y leguminosas (López Garí y Marlasca 2012: 116 y 118).

\section{LA OBLIGACIÓN DE LOS PROPIETARIOS: LOS TRIBUTOS}

Como hemos comprobado, la gran variedad de actividades económicas en las ciudades fenicias requirió una división administrativa del territorio y fomentó un amplio abanico de cargos públicos destinados al cobro de impuestos. Así, el testimonio más antiguo posiblemente sería el grafito documentado en una de las defensas de elefante del pecio de la Campana fechado a finales del siglo VII e inicios del VI a.C., que pudo estar destinado a un recaudador de impuestos (Mederos y Ruiz Cabrero 2004: 276 y 278). Sin embargo, la mayor información sobre los tipos de funcionarios estatales relacionados con este cometido procede de Cartago de los siglos IVII a.C. (Huss 1993: 315), y de Leptis (Liv. XXXIV, 62, -2-3). Así, los rbm ("grandes") serían jefes encargados de la administración financiera, los mhšbm podían corresponder a un especie de contables o controladores, los sprm serían secretarios, los quaestores o praefecti 


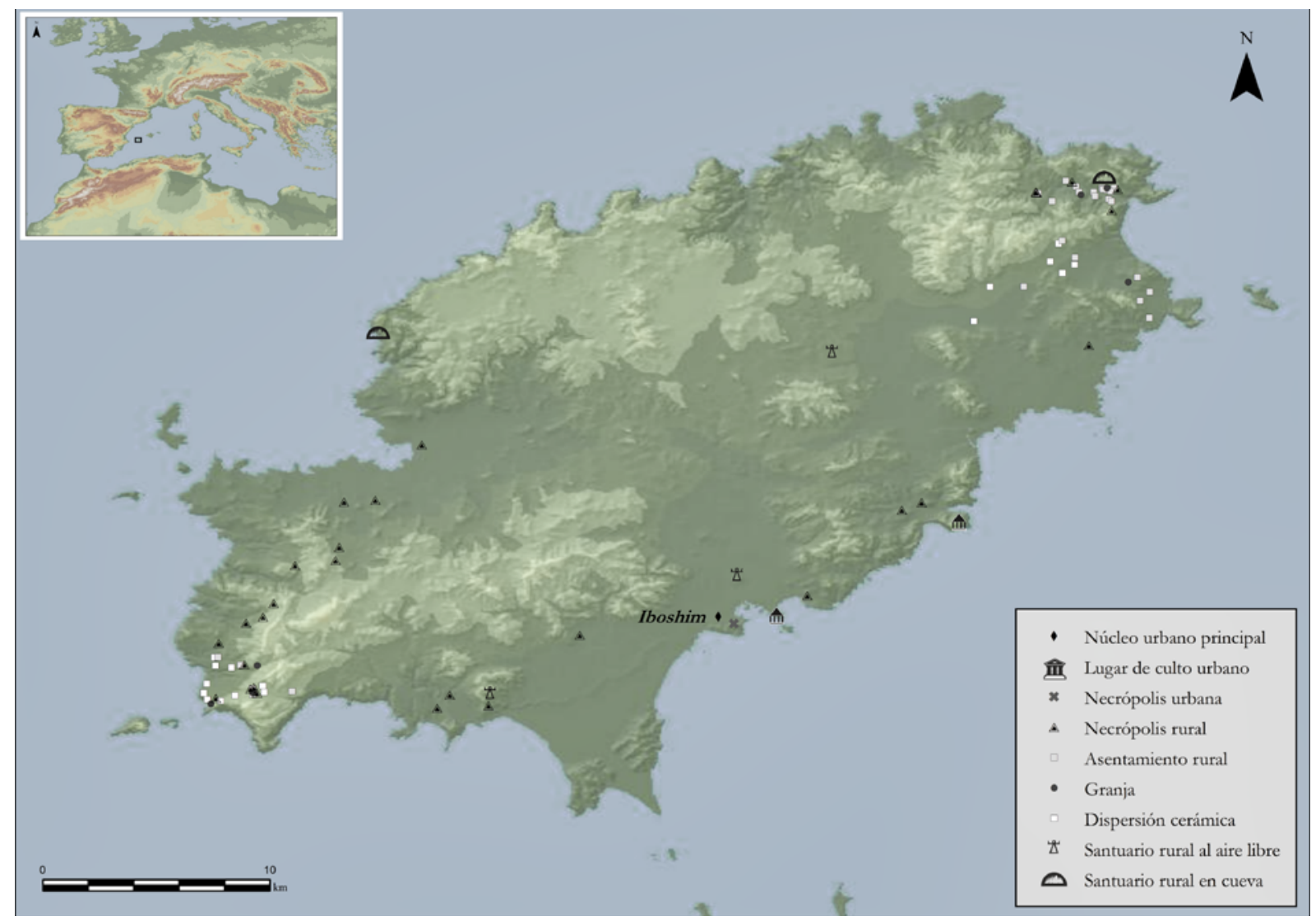

Figura 5. Distribución de asentamientos fenicios en Ibiza entre los siglos IV y III a.C. (a partir de Tarradell y Font 1975; Gómez Bellard 1986; 2008b; Gómez Bellard, Díes y Marí 2011; González Villaescusa y Díes Cusí 1991-1992; Ramon 1995; Puig, Díes y Gómez Bellard 2004; Gómez Bellard, Marí y Puig 2007; Alfaro Giner et al. 2010).

morum, funcionarios fenicios conocidos únicamente por esta terminología latina (Bondì 1995a: 298-299), los 'dr 'krt (CIS I 132) serían algo así como "jefes de estimaciones", los mhzm o inspectores de los mercados, y los šql, que eran recaudadores de siclos (CIS I 6003, RES 15; Ruiz Cabrero 2009: 17).

Este complejo sistema tributario, en origen, debió ser muy diferente, e incluso estar condicionado por las poblaciones autóctonas preexistentes. Así, según Justino (XVIII, 5, 14), Cartago debía pagar tributo a las comunidades autóctonas por explotar sus tierras durante los primeros siglos. Este condicionante se ha querido aplicar también a los enclaves extremo-occidentales donde los artículos de lujo encontrados en las tumbas de las clases dominantes autóctonas podrían haber servido como impuesto (Arteaga 1994: 28). Aunque esta explicación ofrecería una alternativa a la teoría del comercio desigual, la ausencia de fuentes concretas sobre este tema nos impide contrastar esta hipótesis. En cualquier caso, aunque la implicación de las comunidades autóctonas en el pago o cobro de tributos más allá del norte de África es difícil de precisar, sabemos que los asentamientos rurales fenicios tendrían una carga impositiva sobre su excedente productivo (Arteaga 1994: 34; Crouzet 2003: 677).

A partir del I Tratado Romano-Cartaginés en 509 a.C. (PlB. III, 22), el sistema fiscal cartaginés comenzaría a configurarse tal como lo conocemos en los siglos más recientes. El tributo más famoso en estas fechas sería la entrega a Cartago de la cuarta parte de la cosecha de cereales de Cerdeña, que pudo estar destinada a la manutención y alimento del ejército (Gsell 1972: 312; Picard y Picard 1982: 87; Fantar 1993: 266 y 268; Manfredi 2003: 329). También conocemos las dos formas de cargas fiscales impuestas por Cartago a sus territorios sometidos a partir del siglo VI a.C.: uno procedente del campo con una parte de la producción agrícola, en especie (Liv. XXIV, 62, 2-3), y otro del stipendium de los habitantes de las ciudades (Crouzet 2003: 683685 y 698-699). En el primer caso, el impuesto en las 
comunidades rurales era igual al de Cerdeña, es decir, un cuarto del total de la cosecha. Por su parte, las ciudades abonaban la cuantía equivalente a esta. Una excepción la constituían las poblaciones sicilianas de la zona occidental, que pagaban solamente un diezmo de la cosecha (Huss 1993: 315-317).

Precisamente, las excesivas cargas fiscales de las ciudades dependientes de Cartago durante el siglo III a.C. incentivarían el ánimo de sublevación durante la Guerra de los Mercenarios. Aunque en un principio los 'drm, o grandes hombres de Cartago, estarían exentos del pago (Huss 1993: 313), en el transcurso de estos acontecimientos el grueso del impuesto debió de afectar a las grandes propiedades latifundista ya que la comunidad rural no se sublevó (García Moreno 1978: 73 y 75). Durante la II Guerra Romano-Cartaginesa este impuesto llegó a suponer la mitad de las cosechas libias, lo que provocó revueltas en esta zona (PLB. I, 72,1-3). Por su parte, los pueblos númidas que habían sido considerados como aliados por Cartago, fueron sometidos y obligados a pagar otro gravamen (Huss 1993: 315 ), que ascendía al 10\% de la cosecha durante el reinado de Juba I según Plutarco (Caes. 55). Los cálculos de este dato ascienden a unos $105.000 \mathrm{hl}$ de cereal y pudieron representar la base alimenticia de la población cartaginesa (Picard y Picard 1982: 86 y 129).

Más allá de Cartago, una sugerente hipótesis sobre el pago de impuestos fenicios sería la estandarización del volumen de las ánforas a partir del siglo V a.C. Así, en Gadir, se ha planteado una división de la campiña en unidades de producción controladas por núcleos administrativos que pagarían tributos a Cartago con productos envasados en ánforas (Carretero 2007: 171-176, $182,184,201,207,218-220$ y 222-223). Aunque ciertamente el territorio gadirita quedó plenamente configurado en este siglo y comenzaron a estandarizarse las formas anfóricas según el producto contenido (salazón, aceite o vino), la vinculación de estos hechos con Cartago carece de base documental.

Otro territorio bien conocido sería el de Iboshim, donde los tributos se pagarían en especie y estarían controlados por la capital donde, además, existiría el monopolio de la producción de ánforas (Díes y Matamoros de Villa 1991: 823; Costa 1998: 843-842; Ramon 1995: 52; Gómez Bellard 2008a: 63, 68 y 71). Sin embargo, debemos advertir que la presencia de desechos cerámicos de un alfar productor de PE-22, PE-25 y T-8.1.3.3 en Ca N'Andreuet (San Carlos), datado entre el siglo IV y el III a.C. (Ramon 1991: 38), y otras evidencias de la misma índole sin cronología precisa en Ca N'Eloi (Ramon 2001: 97) y en Ce4 (Gómez Bellard,
Díes y Marí 2011: 37 y 98), podrían desmentir el monopolio alfarero del principal puerto.

\section{MAGISTRATURAS FENICIAS PARA CONTROL TERRITORIAL}

Para entender el complejo funcionamiento de las ciudades-estado fenicias debemos remitirnos a la escasa información sobre sus gobiernos. La administración territorial, el aprovechamiento de sus tierras y su fiscalización están indisolublemente unidos al Estado. Aunque la implantación colonial fenicia mantuvo mayoritariamente el sistema de explotación territorial oriental, la ausencia de monarquía implicó el desarrollo de otras instituciones totalmente diferentes (Bondì 1995a: 295; 1995b: 346-347), que comenzaron a consolidarse a partir del siglo VI a.C. (Arteaga 1994: 37, 40-41y 46-48; Manfredi 2003: 331; López Castro 2004: 152-153; Ferrer Albelda y García Fernández 2007: 663664;). Por ello, fue la aristocracia de las principales colonias quien asumió la política administrativa y ostentó los cargos más relevantes (Jiménez Flores y Marín Ceballos 2002: 79).

Sin embargo, la verdadera complejidad administrativa de Cartago aparece entre los siglos V-IV a.C. cuando la capital norteafricana alcanzaría los territorios libios y libiofenicios y surgiría una nueva clase intermedia de funcionarios locales. Este sistema alcanzó su mayor apogeo en el siglo III a.C. bajo el control bárquida debido a su voluntad de integración de los pueblos autóctonos en la estructura estatal cartaginesa, sobre todo libiofenicios (Manfredi 2010: 330). Por ello, fue a partir del siglo III a.C. cuando en los territorios sometidos por Cartago se implantó el cargo de sufete elegido entre los miembros de la oligarquía local de ciudadanos de Cartago (Manfredi 2010: 332-333). La principal causa de este cambio en numerosas ciudades del norte de África, donde se han documentado sufetes entre los siglos III-II a.C., fue la necesidad de un mejor control de la implantación agrícola. Así, se registran sufetes en El Fahs, Bou Arada y El Aroussa, que serían llanuras cerealísticas de gran importancia económica para Cartago (Manfredi 2010: 333). Otro buen ejemplo lo encontramos en Volúbilis, donde se ha documentado una estela de carácter funerario fechada en el siglo I. En ella se hace mención a un sufete que ejerció de escriba en el ejército cuya genealogía remonta a seis generaciones atrás en este cargo. Por este motivo el sufetazgo en Volúbilis pudo haberse implantado entre los siglos IV y III a.C. ya que se trasmitía de generación en 
generación dentro de la misma ciudad (Camps 1960: 423 y 425-426).

Los sufetes tendrían un representante o soken con ciertas connotaciones militares implantado en cada uno de los territorios (Manfredi 2003: 340-341). Así, los cartagineses aseguraban el control gracias a rehenes y guarniciones permanentes en cada territorio dependiente (Crouzet 2003: 701).

Para concluir, otro tipo de magistrados o altos cargos a la cabeza de una comisión serían los $r b$ con funciones políticas y/o religiosas. El significado de este término en plural $(r b b)$ alude a "ser grande" o "ser numeroso" (Sznyzer 2003: 120-122) y, aunque sus funciones no están definidas, sabemos que se trataría un alto rango político con una elevada posición social (Ferjaoui 1991: 479 y 483).

\section{LA INJERENCIA DE LOS TEMPLOS EN LA ADMINISTRACIÓN TERRITORIAL}

No debemos olvidar la estrecha relación entre la religión y el estado en el organigrama gubernamental fenicio. Las autoridades políticas fijaban las tasas sacrificiales y usaban los edificios sagrados como lugar donde tomar decisiones (Ribichini 1985: 36). Incluso, los propios sufetes y/o los senadores (en general, altos magistrados de la ciudad) representaban el "resucitador de la divinidad y esposo de Astarté" (miqin 'elim) (Lipiński 1995: 454-455). La vinculación de las instituciones religiosas con la administración estatal quedaría ratificada por el pasaje de Aristóteles (Pol. II, 11, 3), donde se mencionan las eterías (quizás las mzrhm documentadas en textos epigráficos de Thugga) entre las instituciones de Cartago (Bondì 1995a: 302).

Por otra parte, la relación de los templos con la economía fenicia es un hecho totalmente asumido por la historiografía contemporánea. Se han diferenciado dos tipos de transacciones económicas supeditadas a la figura del templo. Así, el comercio empórico o maqōm, ligado directamente a la ciudad, haría referencia a un lugar, área, distrito, gran edificio o templo (Krahmalkov 2000: 307-309). Tenía un alcance local, regional o internacional, y lo efectuaban individuos con una condición social libre y paridad de condiciones. El otro tipo sería el comercio colonial o aristocrático que implicaba tratados formales de hospitalidad, reciprocidad y fuerza de trabajo (López Castro 2000: 125-128 y 131; 2005: 412).

Además, la sacralización de un espacio y/o la instalación de un santuario heroico, normalmente dedicado a Melqart, implicaba la apropiación progresiva del territorio, simbolizaba la frontera entre la civilización y la barbarie, y estaría ligado al desarrollo de la ciudad (Berche 1967: 76; Bonnet 1988: 409). No en vano, la consagración de un lugar era una de las primeras actuaciones tras la colonización o conquista. Un buen ejemplo lo encontramos en Selinunte, cuya remodelación urbanística tras la toma cartaginesa de la ciudad comenzó por la construcción de un edificio de culto monumental en el área sacra (Chiarenza 2011: 41 y 50).

El templo ostentaría la propiedad del "cinturón agrícola" y lo controlaría gracias a representantes religiosos o inspectores temporales que cobrarían tributos. Además, se ha propuesto que esta institución actuara como centro administrador de la colonización y de las propiedades más allá de esta franja agraria (Alvar y González Wagner 1988: 174-176). Sin embargo, el estudio del territorio, de la distribución de los templos rurales fenicios, y sus respectivas advocaciones, nos ha llevado a replantear el verdadero papel del templo cívico en la organización fenicia en la explotación de los recursos naturales.

Uno de los casos más conocidos sería el templo de Melqart en Gadir, donde pudieron repetirse esquemas tributarios de origen oriental (Arteaga 1994: 32-34 y 36; López Castro 1995: 47). Además, esta titularidad favoreció que los sacerdotes tuvieran la tutela de las actividades económicas y pudieran arrendar las propiedades del templo para su explotación (García Vargas y Ferrer Albelda 2001: 31). También se ha planteado que el templo monumental fortificado costero de Tas-Silg en Malta, destinado al culto de Astarté estuviera conectado con todos los territorios del archipiélago y con las rutas comerciales mediterráneas (Ciasca 1993: 225).

Otra responsabilidad de los templos era la custodia de documentos escritos, que ha quedado patente gracias a las crétulas encontradas en Cartago, Cerdeña o Sicilia. Estos restos eran una pella de arcilla sellada que cerraba un papiro una vez firmado y enrollado. Algunos documentos serían de naturaleza sacra; otros, en cambio, serían de carácter económico como registros notariales públicos de tipo mercantil, registros de la propiedad o contratos privados. Además, en algunas ocasiones, este edificio albergaría la biblioteca de la ciudad (Marín Ceballos y Jiménez Flores 2004: 223225 y 235-236).

El conjunto de crétulas más numeroso encontrado en la actualidad son las 3609 de Cartago, fechadas entre finales del siglo VI y el siglo III a.C., con sellos de tipo egipcio, griego, egiptizante, orientalizante o púnico (Redissi 1991: 20-21). Más antiguo es el caso de Gadir, 
donde la excavación del Teatro Cómico ha registrado un conjunto de crétulas fechado en el siglo VIII a.C., que posiblemente fue quemado en un horno tipo tannûr intencionalmente con sus respectivos documentos económicos y administrativos. El análisis mineralógico de estos sellos ha indicado que al menos uno de ellos fue fabricado con arcilla del Cretácico Superior compatible con las arcillas de este tipo de Chipre, Egipto, Grecia, Turquía, norte de África y Europa alpina (Gener et al. 2012: 165 y 180). El análisis tipológico de los sellos cartagineses, junto con la confirmación petrológica que confirman una realización exógena de los sellos de $\mathrm{Ga}$ dir, avalarían la existencia de lugares específicos, mayoritariamente cultuales, para la custodia de diferentes acuerdos internacionales con otros puntos del Mediterráneo.

En algunos casos, a los rollos de papiro se le añadía otro pegote de arcilla también sellado suspendido por un hilo. Esta variación ha sido interpretada como una prueba para diferenciar los contratos (Martín Ruiz 2007: 75 y 86), o como una forma de distinguir la lengua en la que estaba escrita el documento: bien griego, bien fenicio (Bisi 1986: 298-299).

Sobre el cuerpo de colegiados encargados del templo, sabemos que estaba formado por dos comisiones. La primera eran los šrt $h$ 'šm 'š 1 hmqdšm, diez representantes de las cuestiones sagradas, construcciones y restauraciones de los edificios cultuales elegidos por el propio senado. El segundo cuerpo de magistrados,

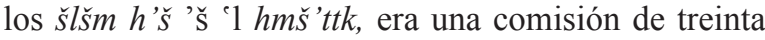
hombres vinculados con los intereses materiales de los templos, ofrendas y tarifas (Jiménez Flores y Marín Ceballos 2002: 80-81). Aunque es difícil definir la influencia de la clase sacerdotal en las actividades políticas, por las inscripciones sabemos que estos altos cargos religiosos estaban ocupados por la élite aristocrática ( $\mathrm{Ri}$ bichini 1985: 36). Incluso, los rb khnm y los rb khnt, dos cargos encargados de la dirección de los sacerdotes consagrados al culto ( $\left.s n^{\prime}\right)$, podrían haber constituido una magistratura en sí (Jiménez Flores y Marín Ceba1los 2002: 83-84).

A medida que los dominios territoriales fenicios alcanzaron su máxima expansión, hacia los siglos IV y III a.C., los espacios sacros rurales fueron diversificándose: encontramos desde espacios al aire libre o abrigos naturales, hasta templos o santuarios ya existentes que fueron monumentalizados o que fueron creados $e x$ novo. La monumentalización del espacio sagrado indicaría su dominio sobre el paisaje donde ejercería un control visual e incluso serviría para determinar el inicio o el fin de un territorio (Bonnet 2008: 674-676).
Nuevamente, un buen ejemplo, lo encontramos en los distritos de Cartago donde la ubicación de los santuarios rurales entre los siglos IV-II a.C. sugiere una preferencia por lugares de frontera (fig. 1). También en Cerdeña, los santuarios rurales han servido de indicadores para establecer límites territoriales (Gharbi 1995: 75; Stiglitz y Tore 1998: 553-561).

Prácticamente en todos los territorios fenicios occidentales se han documentado santuarios en estrecha relación con el control del territorio próximo y la producción agrícola, sobre todo en los siglos de máxima expansión rural fenicia. El ejemplo más llamativo lo encontramos en Antas. donde se erigió un edificio rectangular fechado en el inicio del siglo IV a.C. (Barreca 1969: 36-37; Zucca 1989: 37-38), que se encargaría de controlar y administrar el territorio próximo. También en Cerdeña, el templo de Monte Sirai, contemporáneo a la fundación del hábitat fenicio, fue reestructurado entre los siglos III y II a.C. (Barreca 1964: 27, 30 y 32), y se edificó una estructura rural próxima (Amadasi Guzzo 1966: 84-85, 88 y 91; Barreca 1988: 292). Un caso similar sería el de Ras Il-Wardija (Gozo) donde se documentó una cueva santuario, fechada entre los siglos III y II a.C., con varios grafitos, cinco nichos, una cornisa moldurada y un banco corrido. Este espacio sacro estaba situado próximo a un edificio coetáneo en la parte baja del promontorio que también fue interpretado como un templo a cielo descubierto (Buhagiar 1988: 69-70 y 72-77), pero que podría pertenecer a una granja dada su similitud con las plantas de las instalaciones rurales centro-mediterráneas (Pardo 2015: 149).

El santuario de La Algaida, perteneciente al territorio de Gadir, estuvo frecuentado desde el siglo VI a.C. pero no se construyeron las primeras estructuras hasta el siglo IV a.C. cuando, además, junto al culto a Astarté pudo venerarse también a Tinnit (Ferrer Albelda 2002: 199 y 201-202; 2017: 222). Este complejo cultual constaba de varias habitaciones de 3-5 metros de lado, un pozo y una posible vivienda aledaña (Corzo 2000: 151 y 164). La vivienda era de planta alargada y estaba dividida en tres estancias donde había abundantes restos de fauna, cenizas y ánforas (López Amador y Ruiz Gil 2010: 274). Dadas las características del inmueble, creemos más factible que se trate de un almacén donde se guardaban y administraban las posesiones del templo que procedían de las transacciones económicas que supervisaba y de las tasas impuestas para la realización de ofrendas (Pardo y López Castro 2018: 218).

En el territorio de Baria se fundó el santuario en cueva de Cerro Montroy, seguramente bajo la advocación de Tinnit. Se trataría de un recinto excavado en la 
base geológica, quizás en el siglo IV a.C., por el que se accedería a una cueva aneja. En el oeste también se ha localizado una oquedad que podría corresponder a la misma cueva-santuario y una fauissa revestida con enlucido de cal en el interior. El pleno funcionamiento de este espacio cultual se situaría a finales del III a.C. en función de la cronología de las terracotas y del gran impulso agrícola de Baria en esta etapa (López Castro 2001-2002: 77-82 y 84-86).

Como último ejemplo expondremos el caso de Ibiza, donde la expansión rural de la isla contribuyó a la instalación de numerosos santuarios. El alto número de lugares de culto ha contribuido a pensar que cada núcleo rural ebusitano podría estar asociado a una pequeña instalación cultual a cierta distancia de la zona de hábitat (Ramon 1995: 53). A los primeros momentos de expansión agrícola (Gómez Bellard 2008b: 121122) pertenecería el santuario rural de Puig d'en Valls (Tarradel y Font 1975: 126-127) o Es Culleram, cuyo uso pudo remontarse a las últimas décadas del siglo $\mathrm{V}$ e inicios del IV a.C. (Marín Ceballos, Belén Deamos y Jiménez Flores 2010: 153). En esta cueva, adscrita al culto de Tinnit, aparecieron numerosas figuras antropomorfas que portaban en las manos palomas, cerdos, granadas o cervatillos (Aubet 1968: 28-29, 31-32, 52, 60-61 y 65-66; Marín Ceballos, Belén Deamos y Jiménez Flores 2010: 149) característicos de una economía agraria. Incluso, se ha planteado que la cueva, en su fase más antigua, estuviera dedicada a Tinnit y que en un momento impreciso del siglo IV a.C. se introdujera un nuevo culto a Demeter, con la que compartiría rituales y cuyo testimonio serían las terracotas femeninas representadas con kalathos, un velo, antorchas, lechones y bebés (Van Dommelen y López Beltrán 2013: 284; Marín Ceballos 2015: 208-209 y 213).

Sin embargo, el mayor número de lugares de culto rurales se datarían a partir del siglo IV a.C. como $\mathrm{Ca}$ N'Ursul y Can Pis, pertenecientes a cultos domésticos relacionados con Astarté en su faceta vinculada con la agricultura (Gómez Bellard 2008b: 122 y 127), y S'Era des Matarets donde se localizó una canalización y un muro de grandes sillares fechado entre los siglos III y II a.C. (Gómez Bellard 2000: 355; 2008b: 124-125; Puig, Díes y Gómez Bellard 2004: 30).

Para concluir, los santuarios tophet, que continuaron en uso durante época romana en el norte de África, durante esta fase fenicia tardía estuvieron directamente relacionados con zonas de gran riqueza agrícola (Ruiz Cabrero y Peña 2010: 464). Un ejemplo de los siglos II a.C.-I d.C. sería el tophet al norte de la llanura oriental de Ghorfa y al sur de Jbel Massouge perteneciente al territorio de Cartago desde la I Guerra Romano-Cartaginesa. Esta área sacra formaría parte de una población rural caracterizada por la falta de monumentalización de las estructuras y la presencia de comederos dobles, fragmentos de prensas o contrapesos (Ferjaoui 2007: 12-13, 62-63, 115 y 118-120).

\section{CONCLUSIONES}

Como hemos expuesto, la apropiación de un nuevo espacio para el establecimiento de emigrantes fenicios en las costas occidentales no estuvo restringida al mero lugar urbanizado. Las tierras aledañas quedaron bajo el control y disfrute de estos pobladores y fueron un requisito indispensable para la instalación de nuevos núcleos poblacionales. Además de servir para el autoabastecimiento, existen pruebas arqueológicas que avalan la rentabilidad de estas tierras agrícolas y ganaderas en la producción y comercialización de ánforas de contenido agrícola desde las primeras fases de colonización. El reparto de tierras y la administración de las mismas debieron ser tareas de las altas jerarquías que se encargaron de implantar diferentes cargos para tales funciones. Así, conocemos los relativamente abundantes testimonios epigráficos sobre las magistraturas encargadas del control y fiscalización del territorio en el norte de África. Sin embargo, cuantificar la injerencia estatal y religiosa en la economía agrícola y adscribir la propiedad de la tierra y la extensión de la parcelas es algo que podemos esbozar de manera preliminar y únicamente en algunos territorios fenicios occidentales a partir del actual registro arqueológico.

No es nuevo advertir que el territorio quedaría dividido en espacios privados y tierras comunales para diferentes actividades económicas complementarias. En el primer caso, lo más probable es que la forma de adquisición más difundida fuera la compra directa. En cuanto a su tamaño, la división en pequeñas parcelas o grandes latifundios dependió de la implicación en mayor o menor grado de la aristocracia y de las condiciones orográficas del territorio. Hemos realizado un cálculo aproximado de su distribución gracias a la distancia entre los núcleos rurales y la disposición de hitos territoriales como los monumentos turriformes. Otra variable en la extensión de las propiedades sería la dedicación agrícola a la que estarían destinadas. Así, los latifundios responderían mayoritariamente al monocultivo de cereales, olivos o viñas, mientras que en las pequeñas parcelas se cultivarían todo tipo de productos hortofrutícolas. 
Aunque desconocemos el peso de los tributos en los primeros siglos de colonización, sabemos que fue una de las principales preocupaciones en los gobiernos fenicios debido al grado de especialización que adquirieron las magistraturas en este cometido durante los siglos IV y II a.C. Por ello, podemos presumir que cualquier población en territorio fenicio estaría sometida al pago de impuestos en especie a partir del excedente de su propia producción.

La relación entre la economía rural y los lugares de culto fue evolucionando desde los primeros momentos de colonización hasta los siglos IV-II a.C., cuando se encuadra la mayor expansión agrícola fenicia. La instalación de templos y santuarios en el territorio estuvo justificada por su papel como lugares de referencia en el territorio, mediadores en las transacciones económicas, protectores de acuerdos económicos y, quizás, políticos. De este modo, también pudieron funcionar como puntos de control en las vías de comunicación, espacios de frontera y lugar de encuentro y negociación entre diferentes culturas. Por todo lo expuesto, creemos que no es posible entender el territorio fenicio sin tener en cuenta la participación de la religión en la economía y política de las poléis fenicias.

\section{Agradecimientos}

El resultado de nuestra investigación se ha beneficiado del apoyo financiero del Séptimo Programa-Marco de la Unión Europea (FP7/2007-2013 - MSCA-COFUND) en virtud de la convención de la subvención n²45743 - Programa de becas post-doctorales Braudel-IFER-FMSH, en colaboración con el LABEX-RESMED UMR 8167 y de los proyectos I+D Antes de las Columnas: Málaga en época púnica y su proyección en el SE ibérico y Mar de Alborán (HAR2015-68669-P), dirigido por Bartolomé Mora Serrano, y La Ruta de las Estrímnides. Comercio Mediterráneo e Interculturalidad en el Noroeste de Iberia (HAR2015-68310-P), dirigido por Eduardo Ferrer Albelda y Juan Jesús Martín del Río.

\section{BIBLIOGRAFÍA}

Alfaro Giner, C.; Costa Ribas, B.; Roig Ribas, J.; Ortiz García, J.; Martínez; M. J., Fernández, G. y Antón, M. (2010): “«Timeu»: Un nou projecte d'investigació sobre la producció de llana a l'Ebusus púnica y romana". Cuaderns d'Arqueologia Ebusitana 3: 109-119.
Amadasi Guzzo, M. G. (1966): "L'abitato", en Monte Sirai III. Rapporto preliminare della Missione archeologica dell'Università di Roma e della Soprintendenza alle Antichità di Cagliari della campagna di scavi 1965. Studi Semitici 20: 83-105, tavv. XLIII-XLIX. Roma, Istituto di studi del Vicino Oriente, Università di Roma.

Alvar, J. y González Wagner, C. (1988): "La actividad agrícola en la economía fenicia de la Península Ibérica". Gerión 6: 169-185.

Arteaga Matute, O. (1994): “La Liga púnica gaditana. Aproximación a una visión histórico occidental para su contrastación con el desarrollo de la hegemonía cartaginesa en el mundo mediterráneo", en VIII Jornadas de Arqueología Fenicio-Púnica: Cartago, Gadir, Ebusus y la influencia púnica en los territorios hispanos. Treballs del Museu arqueològic d'Eivissa i Formentera 33 (Ibiza, 1993): 23-57. Ibiza, Museu arqueològic d'Eivissa i Formentera.

Aubet Semmler, M. E. (1968): "La cueva d'Es Culleram (Ibiza)". Pyrenae 4: 1-76.

Baldassari, R. y Fontana, I. (2006): "Le anfore a Pantelleria tra il periodo púnico e la prima età romana", en E. Acquaro y B. Cerasetti, (eds.), Pantelleria punica. Saggi critici sui dati archeologici e riflessioni storiche per una nuova generazione di ricerca. Studi e Scavi. Nouva Serie 15: 41-61. Bologna, Ante Quem.

Barreca, F. (1964): “Gli scavi”, en Monte Sirai-I. Rapporto della missione archeologica dell'Università di Roma e della Soprintendenza alle Antichità di Cagliari: 11-63. Roma, Centro di Studi Semitici.

Barreca, F. (1969): "Lo escavo del tempio", en Ricerche puniche ad Antas. Rapporto preliminare della Missione archeologica dell'Università di Roma e della Soprintendenza alle Antichità di Cagliari. Studi Semitici 30: 9-46. Cagliari, Istituto di Studi del Vicino Oriente.

Barreca, F. (1988): La civiltà fenicio-punica in Sardegna. Studi e Monumenti 3. Sassari, C. Delfino.

Barrionuevo Contreras, F. J. (2001): "Prospección arqueológica superficial del Extremo Noroccidental de la Provincia de Cádiz. Campaña 1997'. Anuario Arqueológico de Andalucía 1998, II Actividades Sistemáticas: 21-29.

Ben Younès, H. (1995): “Tunisie”, en V. Krings (ed.), La civilisation phénicienne et punique. Manuel de recherche : 796-827. Leiden-New York-Lyon, E. J. Brill.

Berche, D. V. (1967): “Sanctuaires d'Hercule-Melqart. Contribution à l'étude de l'expansion phénicienne en Méditerranée". Syria 44, Fasc. 1/2: 73-109. 
Bernardini, S.; Cambi, F., Molinari, A. y Neri, I. (2000): "Il territorio di Segesta fra l'età arcaica e il Medievo. Nuovi dati dalla Carta Archeologica di Calatafimi", en Atti delle Terze Giornate Internazionali di Studi Sull'area Elima, vol. I: 91-139. Gibellina-Erice-Contessa Entellina (1997), Pisa-Gibellina, Scuola normale superiore di Pisa.

Bisi, A. M. (1986): "Un cas très rare d'emploi des "cretulae" dans le milieu phénicien d'Occident. Essai préliminaire d'étude et d'interprétation", en Rencontre Assyriologique Internationale, Cuneiform archives and Libraries LVII (Leiden, 1983): 294304. Istambul, Nederlands Historisch-Archaeologisch Instituut te İstanbul.

Bonanno, A. (2005): Malta: Phoenician, Punic and Roman (Malta's Living Heritage). Malta, Midsea Books.

Bondì, S. F. (1995a): "Les institutions. L'organisation politique et administrative", en V. Krings (ed.), La civilisation phénicienne et punique. Manuel de recherche: 290-302. Leiden-New York-Lyon, E. J. Brill.

Bondì, S. F. (1995b): "La société", en V. Krings (ed.), La civilisation phénicienne et punique. Manuel de recherche: 345-353. Leiden-New York-Lyon, E. J. Brill.

Bondi, S. F. (1995c): "L'organisation politique et administrative", en V. Krings (ed.), La civilisation phénicienne et punique. Manuel de recherche: 268-281. Leiden-New York-Lyon, E. J. Brill.

Bondì, S. F. (2003): "Recenti ricerche fenicie e puniche a Nora", en Secondo Seminario di Studi ItaloTunisino. Fra Cartagine e Roma II: 71-88. Bolonia (2001), Bolonia, Fratelli Lega Editori.

Bonnet, C. (1988): Melqart. Cultes et mythes de l'Héraclès tyrien en Méditerranée. Studia Phoenicia VIII. Lovaina, Peeters.

Bonnet, C. (2008): "Dove vivono gli dei? Note sulla terminologia fenicio-punica dei luoghi di culto e sui modi di rappresentazione del mondo divino", en Atti del Convengo Internazionale Saturnia Tellus. Definizioni dello spazio consacrato in ambiente etrusco, italico, fenicio-punico, iberico e celtico: 673-685. Roma (2004), Roma, Consiglio Nazionale delle Ricerche.

Botto, M.; Finocchi, S.; Melis, S. y Rendeli, M. (2003): "Nora: sfruttamento del territorio e organizzazione del paesaggio in età fenicia e punica", en C. Gómez Bellard (ed.), Ecohistoria del paisaje agrario. La agricultura fenicio-púnica en el Mediterráneo: 151-186. Valencia, Universitat de València.

Buhagiar, M. (1988): “Two archaeological sites-Ras IrRaћeb, Malta, and Ras Il Wardija, Gozo". Melita Historica, New Series 10, 1: 69-87.
Camps, G. (1960): “Á propos d'une inscription punique. Les suffètes de Volubilis aux $\mathrm{III}^{\mathrm{e}}$ et $\mathrm{II}^{\mathrm{e}}$ siècles av. J.-C.”. Bulletin d'archèologie Morocaine IV: 423-426.

Carretero Poblete, P. A. (2007): Agricultura y comercio púnico-turdetano en el Bajo Guadalquivir. El inicio de las explotaciones oleícolas peninsulares (siglos IV-II a.C.). BAR International Series 1703. Oxford, Archaeopress.

Castellani, V. y Mantellini, S. (2006): "Le cisterne campunalate", en Acquaro, E. y Cerasetti, B. (eds.), Pantelleria punica. Saggi critici sui dati archeologici e riflessioni storiche per una nuova generazione di recerca. Studi e Scavi: 113-126. Bologna, Ante Quem.

Chelbi, F.; Paskoff, R. y Trousset, P. (1995): "La Baie d'Utique et son évolution depuis d'Antiquité: una réevaluation géoarchéologique". Antiquités Africaines 31: 7-51.

Chiarenza, N. (2011): 'L'area sacra punica sull'acropoli di Selinunte: nuove proposte”. Sicilia Antiqua 8: 41-53.

Ciasca, A. (1993): "Some Considerations Regarding the Sacrifical Precincts at Tas-Silg". Journal of Mediterranean Studies 3, 2: 225-244.

Ciasca, A. (1995): "Malte", en V. Krings (ed.), La civilisation phénicienne et punique. Manuel de recherche: 698-711. Leiden-New York-Lyon, E. J. Brill.

Corzo Sánchez, R. (2000): "El santuario de La Algaida (San Lúcar de Barrameda, Cádiz) y la formación de sus talleres artesanales", en XIV Jornadas de arqueología fenicio-púnica: Santuarios fenicio-púnicos en Iberia y su influencia en los cultos indigenas. Treballs del Museu arqueològic d'Eivissa $i$ Formentera 46: 147-183. Ibiza (1999), Ibiza, Museu arqueològic d'Eivissa i Formentera.

Costa Ribas, B. (1998): “El proceso de ocupación y explotación del territorio rural en la Ibiza fenicio-púnica. Algunas hipótesis", en Atti del XII Convegno di Studio, L'Africa Romana 12, vol. II: 839-862. O1bia (1996), Sassari, Democratica Sarda.

Costa Ribas, B. y Fernández Gómez, J. H. (2012): “Algunas consideraciones sobre el culto a Melqart en Ibiza", en C. Del Vais (ed.), Epi Oinopa Ponton. Studi sul Mediterraneo antico in ricordo di Giovanni Tore: 613-624. Oristano, S’Alvure.

Costa Ribas, B.; Marí i Costa, V. y Benito, N. (2005): "Territorio y poder: la construcción de una $\chi \omega ́ \rho \alpha$ insular en la Ibiza púnica", en Atti del V Congresso Internazionale di Studi Fenici e Punici, vol. III: 1359-1372. Marsala-Palermo (2000), Palermo, Punto Grafica. 
Crouzet, S. (2003): "Les statuts civiques dans l'Afrique punique. De l'historiographie moderne à l>historiographie antique". Mélanges de l'École Française de Rome. Antiquité 115, 2: 655-703.

Delgado Hervás, A. (2007): “Alimentos para los muertos. Mujeres, rituales funerarios e identidades coloniales". Treballs d'Arqueologia 13: 29-68.

Díes Cusí, E. y Matamoros de Villa, C. (1991): "Introducción al estudio de la arquitectura púnica de Ibiza", en Atti del II Congresso Internazionale di Studi Fenici e Punici, vol. II: 817-824. Roma (1987), Roma, Consiglio nazionale delle ricerche.

Fantar, M. H. (1993): Carthage. Approche d'une Civilisation, vol. I. Tunis, Alif.

Fentress, E. (2009): "The Classical and Early Punic periods”, en E. Fentress, A. Drine y R. Holod (eds.), An Island Through Time: Jerba studies. Volume 1. The Punic and Roman periods An island through time. Journal of Roman archaeology. Supplementary series 71.: 72-74. Portsmouth, Portsmouth, R.I.

Ferchiou, N. (1994): "Le paysage protohistorique et pré-imperial à l'Est et au Sud de Zaghouan (Tunisie)". Antiquités Africaines 30: 7-55

Ferjaoui, A. (1991): “Á propos des inscriptions mentionnant les sufètes et les rabs dans la généalogie des dédicants à Carthage", en Atti del II Congresso Internazionale di Studi Fenici e Puniche, vol. II: 479-483. Roma (1987), Roma, Consiglio nazionale delle ricerche.

Ferjaoui, A. (2007): Le sanctuaire de Henchir el-Hami. De Ba'al Hammon au Saturne Africain. Ier s. av. J.C.-IVe s. ap. J.-C.. Túnez, Institut National du Patrimoine.

Ferrer Albelda, E. (2002): “Topografía sagrada de Extremo Occidente: santuarios, templos y lugares de culto de la Iberia púnica", en E. Ferrer Albelda (ed.), Ex Oriente Lux: las religiones orientales antiguas en la Península Ibérica. Spal Monografías II: 185-217. Sevilla, Secretariado de Publicaciones de la Universidad de Sevilla.

Ferrer Albelda, E. y García Fernández, F. J. (2007): “El fenómeno de la polis en el mundo púnico occidental”, en Las aguas primigenias. El Próximo Oriente Antiguo como fuente de civilización. Actas del IV Congreso Español de Antiguo Oriente Próximo: 653-667. Zaragoza (2006), Zaragoza, Instituto de Estudios Islámicos y del Oriente Próximo.

Ferrer Albelda (2017): "Las comunidades púnicas en Iberia”, en C. Pérez (coord.), La protohistoria en la Península Ibérica. Historia de España II. Historia Antigua: 149-340. Madrid, Istmo.
Finocchi S. (2013): "Dalla Nora fenicia alla Nora punica e oltre". LANX. Rivista della Scuola di Specializzazione in Archeologia - Università degli Studi di Milano 14: 157-179.

García Moreno, L. A. (1978): “La explotación del agro africano por Cartago y la Guerra Líbica”, en Actas del Coloquio: Colonato y otras formas de dependencia no esclavistas. Memorias de Historia Antigua 2: 7180. Oviedo (1978), Oviedo, Universidad de Oviedo.

García Vargas, E. y Ferrer Albelda, E. (2001): "Las salazones de pescado en la Gadir púnica: estructuras de producción”. Laverna XII: 21-41.

Gener Besallote, J. M.; Navarro García, M. A.; Pajuelo Sáez, J. M.; Torres Ortiz, M. y Domínguez Bella, S. (2012): "Las crétulas del siglo VIII a.C. de las excavaciones del solar del Cine Cómico (Cádiz)”. Madrider Mitteilungen 53: 134-185.

Gharbi, M. (1995): "La forteresse punique et son territoire: réflexion sur la présence punique en Sardaigne et en Tunisie", en Actes du III Congrès International des Études Phéniciennes et Puniques, vol. II: 71-82. Túnez (1991), Túnez, Institut National du Patrimoine Gómez Bellard, C. (1986): "Asentamientos rurales en la Ibiza púnica", en G. del Olmo Lete y M. E. Aubet (dirs.), Los Fenicios en la Península Ibérica. Arqueología, cerámica y plástica, vol. I. Aula Orientalis 3: 177-192. Sabadell, Ausa.

Gómez Bellard, C. (2000): "Avance del estudio de un paisaje rural púnico y romano: El Cubells-Cala d'Hort (Ibiza)", en Actas del IV Congreso Internacional de Estudios Fenicios y Púnicos, vol. I: 353-362. Cádiz (1995), Cádiz, Universidad de Cádiz.

Gómez Bellard, C. (2006): "La explotación rural fenicia y púnica en el Mediterráneo Occidental”. Tema Monográfico. Tiempos de Púrpura. Málaga Antigua y Antigüedades Hispanas I. Mainake 28: 177-187.

Gómez Bellard, C. (2008a): "Ibiza: the Making of New Landscapes", en P. Van Dommelen y C. Gómez Bellard (A.A.), Rural Landscapes of the Punic World. Monographs in Mediterranean Archaeology 11: 4475. Londres, Equinox Pub.

Gómez Bellard, C. (2008b): "Espacios sagrados en la Ibiza púnica", en Atti del Convengo Internazionale Saturnia Tellus. Definizioni dello spazio consacrato in ambiente etrusco, italico, fenicio-punico, iberico e celtico: 119-132. Roma (2004), Roma, Consiglio Ramon Torres, J. (1991): Las ánforas púnicas de Ibiza. Ibiza, Conselleria d'Educació i Cultura. 
Ramon Torres, J. (1995): Ses Païses de Cala d'Hort. Un establiment rural d'època antiga al Sud-Oest d'Evissa. Ibiza, Consell Insular d'Eivissa i Formentera.

Ramon Torres, J. (2001): "El asentamiento rural y los asentamientos púnicos de Ca n'Eloi (Santa Eulària des Riu. Eivissa)". Rivista di Studi Fenici 29, 1: 53101.

Redissi, T. (1991): "Les empreintes de sceaux égyptiens et égyptisants de Carthage". Centre d'études et de documentation archéologique de la conservation de Carthage (CEDA Carthage) 12: 13-24.

Ribichini, S. (1985): "Temple et sacerdoce dans l'économie de Carthage", en Actes du II Colloque sur l'histoire et l'archéologie de l'Afrique du Nord, Bulletin archéologique du Comité des travaux historiques et scientifiques 19 B: 29-37. Grenoble (1983), Paris, C.T.H.S.

Ruiz Cabrero, L. A. (2009): "Sociedad, Jerarquía y clases sociales de Cartago", en XIII Jornadas de Arqueología fenicio-púnicas: Instituciones, demos y ejército en Cartago.. Treballs del Museu arqueològic d'Eivissa i Formentera 64: 7-73. Ibiza (2008), Ibiza, Museu arqueològic d'Eivissa i Formentera

Ruiz Cabrero, L. y Peña Chocarro, V. (2010): "La pervivencia de los tofet como elemento de cohesión territorial tras la caída de Cartago", en Colloque International: Carthage et les autochtones de son empire du temps de Zama: hommage à Mhamed Hassine Fantar: 459-470. Siliana y Túnez (2004), Túnez, Institut National du Patrimoine. Sagona C. (2002): The Archaeology of Punic Malta. Ancient Near Eastern Studies. Supplement 9. Lovaina, Peeters.

Stiglitz, A. y Tore, G. (1998): "Realtà rurali e urbane: territorio e urbanizzazione nella Sardegna fenicio-punica", en Atti del XII Convegno di Studio, L'Africa Romana 12, vol. II (Olbia 1996): 549-563. Sassari, EDES.

Stuijts, I. (1991): "Kinderoffers in de tophet (Carthago); houtskoolonderzoek". Paleo-aktueel 2: 58-61.

Suárez Padilla, J.; Escalante Aguilar, M. M.; Cisneros García, M. I.; Mayorga Mayorga, J. y Fernández Rodríguez, L. E. (2007): “Territorio y urbanismo fenicio-púnico en la bahía de Málaga. Siglos VIII-V a.C.", en J. L. López Castro (ed.), Las ciudades fenicio-púnicas en el Mediterráneo Occidental: 209-231, 562-567. Almería, CEFYP-Universidad de Almería.

Sznyzer, M. (2003): “Á propos des structures sociales et politiques de la cité punique. Le «rab» et le «sufete», le «citoyen» et l»«esclave»", en $\mathrm{VIII}^{e} \mathrm{Co}$ lloque International sur l'Histoire et l'Archéologie de l'Afrique du Nord. ler Colloque International sur l'Histoire et l'Archéologie du Maghreb. L'Afrique du Nord Antique et Médiévale: 115-123. Tabarka (2000), Tunis, Comité des travaux historiques et scientifiques.

Tarradell, M. y Font, M. (1975): Eivissa Cartaginesa. Biblioteca de Cultura Catalana 13. Barcelona, Curial.

Tsirkin, J. B. (1986): "Carthage and the problem of polis". Rivista di Studi Fenici 14, 2: 129-141.

Van Dommelen, P. (1998): On Colonial Grounds. A Comparative Study of Colonialism and Rural Settlement in First Millennium BC West Central Sardinia. Leiden, Faculty of Archaeology Leiden University.

Van Dommelen, P. (2006): "Punic farms and Carthaginian colonists: surveying punic rural settlement in the Central Mediterranean". Journal of Roman Archaeology 19, 1: 7-28.

Van Dommelen, P. y Gómez Bellard, C. (2008a): "Agrarian Landscapes and Rural Communities", en P. Van Dommelen y C. Gómez Bellard (A.A.), Rural Landscapes of the Punic World. Monographs in Mediterranean Archaeology 11: 202-230. Londres, Equinox Pub.

Van Dommelen, P. y Gómez Bellard, C. (2008b): "Defining the Punic World and its Rural Contexts", en P. Van Dommelen y C. Gómez Bellard (A.A.), $R u$ ral Landscapes of the Punic World. Monographs in Mediterranean Archaeology 11: 1-21. Londres, Equinox Pub.

Van Dommelen, P. y López Beltrán, M. (2014): "Hellenism as subaltern practice: rural cults in the $\mathrm{Pu}-$ nic world", en J. R.W. Prag y J. C. Quinn (eds.), The Hellenistic West. Rethinking the Ancient Mediterranean: 273-299. Cambridge, Cambridge University Press.

Vella, N. C. (2005): "Phoenician and Punic Malta". Journal of Roman Archaeology 18, 2: 436-450.

Vidal González, P. (1996): La isla de Malta en época fenicia y púnica. BAR International Series 653. Oxford, Tempus Reparatum.

Wolff, S. R. (1996): "Oleoculture and Olive Oil Presses in Phoenician North African", en D. Eitam y M. Heltzer (eds.), Olive Oil in Antiquity, History of the Ancient Near East Studies 7: 129-139. Padova, Sargon.

Zucca, R. (1989): Il Tempio di Antas. Sardegna Archeologica. Guide e Itinerari 11. Sassari, Delfino.Nazionale delle Ricerche. 